\title{
El debate social sobre las fuentes de energía: representaciones semánticas y gestión social de los conocimientos $^{*}$
}

\author{
The social debate on energy sources: semantic representations \\ and social management of knowledge
}

VICENT SALVADOR

UNIVERSITAT JAUME I

Recibido: 22/12/2013

Aceptado: 01/03/2014

ABSTRACT: This paper examines the structure of the discursive space where the social debate about energy sources takes place. The space structure is configured by many factors as interdiscursive axes (risk/danger, prosperity, dirtiness, ecological alternatives for the future), main purposes of discourse practices (popularization, persuasion), textual genres and semantic representations involved in the shared knowledge and values (doxa) about the different energy sources: fossil, nuclear and renewable sources. Lexical associations, metaphors and euphemisms/dysphemisms are relevant tools to convey the points of view of every attitude taken in the frame of the social debate. The corpus of the analysis consists of books and articles about energies and their convenience of inconvenience for the planetary society, included texts devoted to the theory of Gaia and the programs of degrowth. A theoretical concept applied in this analysis is the notion of social management of knowledge, which implies not just the popularization of scientific-technological knowledge but also the mechanisms of argumentation and persuasion employed in the construction of the public opinion.

Keywords: sources of energy, social debate, social management of knowledge, semantic representations, shared doxa.

(*) El presente trabajo se inscribe en el proyecto de investigación «El discurs divulgatiu en català i en espanyol: gèneres, estils i estratègies argumentatives en la gestió social dels coneixements» (UJI-Fundació Bancaixa PI 1B2011-53) y así mismo en el proyecto ministerial de investigación «Retórica constructivista: discursos de la identidad» (FFI2013-40934-R). 
RESUMEN: Este trabajo estudia la estructura del espacio discursivo donde se inserta el debate social sobre las energías, un espacio configurado por factores como ejes interdiscursivos (riesgo/peligro, prosperidad, suciedad, alternativas de futuro), propósitos de las prácticas discursivas (divulgación, persuasión), géneros textuales implicados y representaciones semánticas integradas en la doxa (conocimientos y valores compartidos) sobre las diferentes fuentes de energía: fósiles, nucleares, renovables... Connotaciones léxicas, metáforas y eufemismos/disfemismos son elementos relevantes para la construcción de los puntos de vista y la valoraciones en el marco del debate social. El corpus consiste en libros y artículos sobre las energías y sus ventajas e inconvenientes para la sociedad y el planeta, incluyendo la teoría de Gaia y las propuestas de decrecimiento. Un concepto teórico aplicado en este análisis es el de gestión social de los conocimientos, que junto a la divulgación científico-tecnológica incluye los mecanismos argumentativos y persuasivos de construcción de la opinión pública.

Palabras clave: fuentes de energía, debate social, gestión social de los conocimientos, doxa, representaciones semánticas.

L'énergie nous pose non seulement des problèmes techniques et économiques, mais aussi indirectement les problèmes des transports, de l'habitat, de la production, de la consommation, de la ville, du mode de vie. Elle nous amène à considérer des problèmes clés de société.

La société est un complexe dans le sens où le mot complexus signifie «ce qui est tissé ensemble» et, si nous suivons les fils énergétiques, nous arrivons au complexe d'ensemble.

EDGAR MORIN

\section{Para una articulación del espacio del debate}

La energía -nombre abstracto de origen griego, desterminologizado en buena medida por su uso común, polisémico en función de los contextoscorresponde a un concepto central de la física y constituye hoy una de las áreas más activas del debate social. En efecto, alrededor de la energía y sus modalidades se teje una red de conocimientos teóricos y aplicaciones tecnológicas de trascendencia enorme para la macroeconomía de los estados y para la microeconomía de los ciudadanos. La organización de la vida social gira en cierto modo alrededor de la disponibilidad de las energías, de su coste, de 
su consumo, de los riesgos calculables o de la peligrosidad incontrolada que pueden comportar en ciertos «casos» (cf., para la diferencia semántica entre «riesgo» y «peligro», Migliorati, 2006: 12-16).

Además, el debate energético no puede sustraerse a una inobviable dimensión planetaria, ya que la asequibilidad física y económica de las fuentes de energía, su transmisión a través del espacio geográfico, las posibles consecuencias catastróficas o los conflictos armados que desatan, son factores que imposibilitarían una aproximación adecuada si se prescindiera de una concepción globalizadora del asunto. Dicho de otro modo: su trascendencia es tan amplia que afecta a los hogares concretos, a la paz mundial o al equilibrio del ecosistema planetario total. Los jugosos dividendos que arroja su gestión hacen de las fuentes de energía un arma de presión y hasta de chantaje entre los países, un objeto de codicia para los agentes de la mundialización mercantilista, un mecanismo clave para el control del mercado y del poder en la Tierra. Su tratamiento exige, en consecuencia, una perspectiva multidisciplinar que incluya la visión científico-tecnológica, la economicista, la sociopolítica y también el estudio de los discursos en los que se vehicula la comunicación social.

Situándonos ahora en este último terreno, se puede decir que las prácticas sociodiscursivas que tienen como tema la energía presentan finalidades diferenciables: $a$ ) la informativa (noticias periodísticas, acontecimientos, descubrimientos...); b) la de circulación y divulgación de los conocimientos especializados sobre las energías; $\mathrm{y}$, en tercer lugar, $c$ ) la vehiculación de un debate público, que no solo se materializa en intercambios polémicos concretos y explícitos, sino en el conjunto de puntos de vista valorativos que se manifiestan en el seno de un vasto espacio académico y mediático donde esta temática exige posicionamientos definidos. Las tres directrices se combinan entre sí, claro está, e interactúan.

Así, la noticia de un hecho grave -por ejemplo un suceso de contaminación marina por naufragio de un petrolero o un accidente nuclear- desencadena automáticamente la necesidad de divulgar en el espacio mediático, con el auxilio de voces expertas, las características del hecho, sus orígenes y sus previsibles consecuencias. Se produce, pues, una demanda de explicación científica de los hechos, y esa actividad divulgadora sustenta la confrontación entre distintas posturas valorativas, es decir, el debate, el cual exige una fundamentación - generalmente mediada- en datos científicos, de modo que la divulgación de los conocimientos especializados se multiplica tras cada suceso catastrófico (CEDISCOR, 1992). En ese contexto, la actividad divulgadora difícilmente puede ser neutral, sino que necesariamente se interpreta en el cuadro del debate social previo y se convierte en instrumento argumentativo para unas u otras tomas de posición. El affaire del naufragio del Prestige, relativamente circunscrito 
al ámbito español, o los accidentes nucleares de Chernóbil y de Fukushima, ambos con alcance inmediatamente universal, son casos que ejemplifican a la perfección esta complejidad de factores.

En efecto, las catástrofes de todo tipo suelen ser el mecanismo que dispara el interés mediático por la transmisión de conocimientos especializados, aunque, en el caso de Fukushima, un solvente estudio sobre el tema señala que la prensa española concedió mucho más espacio y énfasis a los aspectos económicos y políticos (García Mestres et al., 2012). De cualquier manera, lo de Fukushima motivó en 2011 reacciones políticas y decisiones urgentes en distintos estados, por ejemplo en Alemania, y su trascendencia fue más allá, puesto que determinó un giro relevante, un punto de inflexión en la opinión pública mundial, que había ido serenándose en los años anteriores al accidente respecto a la peligrosidad de las centrales nucleares y la posible asunción de los correspondientes riesgos. De hecho, en un periodo anterior al suceso de Fukushima (marzo de 2011) se produjo una «tímida primavera nuclear»o «nuclear renaissance», com la ilusión de que al final se podía «domesticar la nueva fuente de energía», però la persistente asociación con su uso bélico (o al menos prebélico) determina que la mayoia de los ciudadanos europeos percibieran esta energía, incluso antes de Fukushima, «más como una amenaza que como un beneficio» (De Paoli, 2013: 218). Como consecuencia de este suceso, la aceptación social de la energía nuclear descendió de manera inmediata y drástica, ya que, aunque la probabilidad de accidentalidad grave sea reducida (en Fukushima se concitaron diversos factores accidentales, difíciles de predecir), las consecuencias de un acontecimiento así son terribles, con lo cual el riesgo atómico tiende a convertirse en auténtico peligro, de acuerdo con una ecuación de cálculo: «Els factors principals de desenvolupament tindran a veure amb l'acceptació social d'una tecnologia altament estigmatitzada per la forma com va néixer i en la qual l'equació de risc (risc = probabilitat $X$ conseqüències), on el factor conseqüències és molt elevat, encara que la probabilitat d'accidents sigui baixa» (Bruno, 2012: 59).

En las circunstancias actuales (escribo desde la altura histórica de 2014), hay distintos flujos interdiscursivos que cruzan el marco del debate social sobre estos temas y configuran el espacio de lo opinable (Amossy, 2006: cap. 3 ), al tiempo que contribuyen a diseñar identidades personales o colectivas en función de las posiciones que estas ocupan en dicho espacio y en relación con las posturas adoptadas en el debate.

Uno de estos ejes (1) remite a la finitud de fuentes de energía, que disponen de existencias limitadas en el planeta (especialmente las fósiles), las condiciones de su disponibilidad y de su gestionabilidad. Así, por ejemplo, los 
yacimientos de petróleo o de gas se consideran bienes escasos (y por tanto son objeto de codicia y motivo de conflictos internacionales), agotables y a menudo difíciles de gestionar (suciedad contaminante, transportabilidad dificultosa, riesgo de efectos sobre la atmósfera o sobre los mares...). Se trata de riesgos a medio o largo plazo, previsibles pero no inminentes, como el agotamiento de los yacimientos, el incremento del efecto invernadero o la contaminación de los mares. Otro de los ejes interdiscursivos (2) corresponde al peligro nuclear, de proporciones aterradoras e incluso apocalípticas frente a los riesgos derivados de las energías fósiles. Además de la zozobra permanente por el destino de los desechos y su práctica indestructibilidad, que hipoteca la seguridad de la humanidad futura, existe el peligro de un accidente fortuito, impredecible, que podría ser inminente en cualquier momento. El tercer eje (3) articula alternativas de futuro, más o menos esperanzadoras desde una concepción innovadora que apunta hacia las propuestas ecológicas de respeto al medio ambiente, y con un grado u otro de radicalidad. Podríamos sintetizar así los rasgos característicos de estos tres ejes:

1) Finitud y efectos contaminantes de las energías convencionales: riesgo a medio o largo plazo, científicamente predecible y calculable

2) Peligro nuclear: imprevisibilidad y efectos apocalípticos

3) Alternativas ecológicas de futuro, más o menos radicales

Si alrededor de los dos primeros ejes se articulan dos tipos de fuentes que compiten entre sí, el tercero de ellos se configura como alternativa de futuro en positivo frente a los riesgos/peligros que implican los otros dos, percibidos como negativos, y se define por oposición a estos, lo que supone un disenso esencial que encuadra los términos del debate. Este marco de debate puede generar polémicas concretas, controversias explícitas, pero su configuración como campo de fuerzas determina que cualquier toma de posición adquiere inmediatamente un valor diferencial y opositivo respecto a las otras opciones.

\section{Dimensiones pragmáticas y géneros discursivos}

Para situar el campo del debate energético habría que considerar no solo esos ejes interdiscursivos que lo atraviesan y posibilitan así unas referencias cruzadas entre las distintas posiciones adoptadas, sino que también los géneros en los que esas posiciones se manifiestan y, previamente, una serie de factores pragmático-discursivos que determinan la tipología de los textos y su contex- 
tualización. Comenzaré por mostrar de una manera estructurada estos factores, tal como se ve en el cuadro siguiente:

\section{Discurso sobre las energías \\ (a través de distintos géneros)}

\section{Divulgación de} conocimientos

Explicación

\section{DEBATE}

Inserción del punto de vista, ideologia

Argumentación $i$

persuasión emocional

\section{Investigación científica}

\section{Intereses económicos}

Así pues, encontramos en la columna de la izquierda del cuadro tres conceptos relacionados con los conocimientos científicos especializados, unos conceptos que podemos leer de manera ascendente: $a$ ) resultados de la investigación científica; $b$ ) la explicación como secuencia textual dominante, y $c$ ) la orientación divulgativa que determina una serie de propiedades del lenguaje utilizado en los textos y de la configuración de estos. En la columna de la derecha encontramos: $a^{\prime}$ ) los intereses económicos, que están en la base del contexto del debate; $b^{\prime}$ ) el esfuerzo persuasivo que se realiza por medio de las secuencias argumentativas y las adherencias emocionales que se movilizan, y $c^{\prime}$ ) en el extremo superior, la expresión de los distintos puntos de vista y de la ideología donde se encuadran, que es tanto más influyente en la medida en que se transmite por implícitos asumidos y por medio de las orientaciones valorativas inherentes a las expresiones lingüísticas escogidas. En el centro del esquema, relacionado con todos los puntos, se hallaría el área de las eventuales interacciones polémicas pero, sobre todo, el marco general del debate social 
sobre las energías, que se fundamenta en estos factores y que está recorrido por las tres corrientes interdiscursivas antes presentadas.

En ese espacio complejo es donde se sitúa cualquier intervención sobre la cuestión de las energías en nuestro mundo. Un espacio cuyo trasfondo integra, por un lado, el conocimiento científico, su autoridad simbólica, su difusión entre los ciudadanos mediante explicaciones y reformulaciones divulgadoras, $\mathrm{y}$, por otra parte, los puntos de vista en conflicto, las ideologías subyacentes, las estrategias argumentativas/persuasivas y los intereses socioeconómicos que condicionan el conjunto. En síntesis: los saberes, el lenguaje, las posturas en conflicto y los intereses de todo tipo.

Ahora bien, convendría además dar un vistazo a la diversidad de géneros o tipos de discurso a través de los cuales las intervenciones se vehiculan. Por ejemplo, puede tratarse de un trabajo estrictamente científico, pero, por poco que se analice críticamente, es evidente que este tipo de discurso tiene una retórica que lo legitima y le confiere autoridad social, y que en esos textos (bien sean publicaciones en revistas especializadas, ponencias congresuales o manuales universitarios) habita siempre, muy en el fondo, una especie de complejo nudo de víboras donde se entrelazan intereses materiales, posiciones académicas y opciones ideológicas. Existe, asimismo, la modalidad divulgativa que toma cuerpo genérico en opúsculos, en reportajes periodísticos, en documentales. Hasta llegar al manifiesto, al panfleto que mueve directamente a la acción, o a la propaganda descarada... Y todo eso sin olvidar la literatura (con sus derivados o paralelos cinematográficos), que alimenta el imaginario colectivo (destrucción mundial, paraíso perdido, utopía futura) y que contribuye a divulgar los conocimientos científicos sobre el tema y a diseñar los límites de la ética social (injusticias distributivas, explotación, expolio de la naturaleza). Es a través de estos géneros y de sus convenciones asumidas como el debate energético se plasma en textos, se articula y se difunde.

Aquí me interesaré principalmente por los géneros escritos divulgativos, a partir de los libros y artículos sobre esta temática que integran el corpus del presente trabajo (véanse en la bibliografía las referencias de tema energético, que, dado su carácter mixto académico-divulgativo y al mismo tiempo de opinión valorativa e incluso a veces programático, han sido utilizadas aquí como bibliografía primaria y secundaria a la vez). Son textos que pretenden la difusión del conocimiento pero también, de una manera u otra, la toma de postura en el espacio del debate, el compromiso social o gremial, la defensa de una postura ante la opinión pública o incluso la arenga para fomentar el cambio con carácter calculadamente práctico o con aire mal disimuladamente 
utópico. Seguiremos ahora el itinerario analítico a través de los distintos tipos de energía que son objeto de dichos textos.

\section{El discurso sobre las convencionales y las nucleares: doxa, léxico y metaforización}

Al examinar el corpus indicado, salen a la luz una serie de representaciones semánticas que resultan habituales en otros géneros y que responden a los ejes interdiscursivos antes citados. Estudiaremos ahora cómo esas representaciones semánticas del mundo de las energías vehiculan las distintas posiciones y se convierten en recursos expresivos y persuasivos en el marco del debate social sobre el tema. Para ello conviene atender a la doxa u opinión socialmente asumida, que posibilita el diálogo y el debate (Amossy, 2006: cap. 3) y a las expresiones verbales que la vehiculan (léxico connotado eufórica o disfóricamente, eufemismos, proyecciones metafóricas) como instrumento cognitivo y persuasivo (Semino, 2008; Bustos, 2014). Ambos aspectos están estrechamente relacionados, ya que la doxa se manifiesta mayoritariamente en el ámbito del léxico y de la fraseología, mientras que las expresiones lingüísticas, literales o metafóricas, tienden, por mera eficacia comunicativa, a asumir los valores compartidos que se integran en la doxa.

Como hemos visto, las energías convencionales (de origen fósil, como el carbón, el petróleo o el gas) se asocian en el interdiscurso con la finitud, la contaminación y el riesgo a largo plazo, pero al mismo tiempo se presentan como difícilmente prescindibles en el futuro inmediato. Diríamos que el elemento dóxico que las caracteriza es el de una riqueza con fecha de caducidad y que comporta un daño inevitable que tiende a ignorarse. No en vano la explotación de estas fuentes ha permitido históricamente un desarrollo económico vertiginoso, principalmente con el aprovechamiento del petróleo, y una prosperidad aparentemente ilimitada, al menos para las economías nacionales y las clases sociales que tenían fácil acceso (y barato) a esa fuente. El petróleo se ha asociado, en la literatura y en el cine, a la riqueza y al progreso, a la sociedad de la opulencia que era deseada o envidiada por los que no gozaban aún de ella, mientras que su vinculación a la idea de riesgo es posterior, y surge sobre todo al tratar la contaminación atmosférica, marina o de los espacios verdes, y, muy recientemente, en relación con el fracking que ha provocado una justificada alarma por sus efectos geológicos, hasta con movimientos sísmicos.

Las energías convencionales se vinculan así -tanto para sus defensores como para sus detractores- a ciertas expresiones, simples o fraseológicas, 
con un grado u otro de figuratividad, y que a menudo constituyen auténticas catacresis acuñadas para definir un objeto de discurso que es imprescindible manejar para hablar de ecología: «cambio climático», «calentamiento global» o «efecto invernadero» (francés: «effet de serre»; ingl.: «greenhouse effect»; portug.: «efeito de estufa») (Carvalho, 2013). En otras ocasiones se trata de creaciones figurativas no necesarias pero que aportan un colorido y unas resonancias particulares, tanto si se trata de tópicos arraigados como de imágenes más originales: «oro negro», «cáncer de la biosfera», «umbral del calentamiento irreversible», «culto al crecimiento», etc. Ciertamente, el discurso sobre las energías convencionales no ha generado una panoplia vistosa de imágenes metafóricas, y muchas veces estas son empleadas preferentemente con intención polémica, desde los planteamientos críticos de los defensores de otras posturas. Pero es indudable que el concurso de tales expresiones facilita pensar ese ámbito energético y verbalizarlo a través de un interdiscurso omnipresente.

En el ámbito de las nucleares, las expresiones metafóricas son más numerosas y atrevidas (aunque también más eufemísticas, cuando aparecen en boca de sus defensores). Sin duda, ese eje interdiscursivo ofrece un perfil más proclive a la efervescencia imaginativa. La energía nuclear, en efecto, presenta una doble faz, es un Jano moderno. Por un lado, implica un factor eufórico de descubrimiento científico de punta y utilidad social, una cierta «limpieza» ambiental (en contraste con las fuentes fósiles), orgullo tecnológico y monumentalidad (las centrales son ciclópeas y futuristas, gigantes desafiadores). Por el otro, suscitan la imagen del peligro incontrolable, de la guerra aniquiladora y hasta de las llamas del infierno. La energía atómica está marcada por su uso como arma macrodestructiva, que es su pecado original, su estigma. Su desafío a los dioses es prometeico, y el castigo es la amenaza continua de la devastación.

El cine del «oro negro» dio frutos moderados, la epopeya del sueño americano de enriquecimiento (Gigante, por ejemplo) y documentales que muestran la suciedad contaminante y la depredación de la naturaleza, del reino vegetal y del animal, el riesgo -lejano, eso sí- de un cambio climático empobrecedor... El cine de temática atómica, por contra, es el día después de la muerte de la humanidad, es el absoluto irracional, la ambición luciferina que nos estalla entre las manos, y también el misterio que funde el amor con la muerte en una explosión universal (recordemos Hiroshima, mon amour, con su alternancia de escenas de sexo y de explosión atómica). Naturalmente, los defensores de las nucleares se decantan más por activar el horizonte de la tecnología eficiente, la relativa limpieza de su uso y el control del riesgo, y la eufemización de los factores negativos («residuos nucleares», «índice de seguridad», «riesgo controla- 
do»), pero sus antagonistas, que sacan provecho de la faceta oscura, parecen a veces sentir la misma fascinación de los hombres medievales por las gárgolas góticas que pintaban el pecado tan al vivo... Las metáforas que encontramos en el corpus suelen corroborar esa dimensión de deseo reprimido, de fascinación invertida de signo. Suicidio colectivo, tumbas, oscuridad y conspiraciones son, entre otras, representaciones semánticas habituales en este eje interdiscursivo. Se habla, así, de «la potencia suicida del arma nuclear», «cementerios nucleares», «sarcógafos», «mantener encendidas las luces de la civilización» (contra el apagón atómico), «el lobby nuclear», y también, como un efecto boomerang, «el lobby antinuclear» (que «va contra el consenso científico»), «tanta urticaria atómica» (aplicado a sus adversarios), etc.

\section{Las alternativas y sus representaciones semánticas}

\subsection{Las energías renovables}

Las renovables, a diferencia de los otros dos tipos de energía examinados, se presentan como limpias (y de hecho a veces se denominan así), como procedentes de fuentes no finitas y como beneficiarias de una sofisticada tecnología de futuro, aunque no renuncian al toque de cálida humanidad («bicitaxis», «cocinas solares» o «molinos de viento» como designación de los aerogeneradores). De hecho, una energía renovable como la eólica goza de larga tradición en la historia de la humanidad, sea en la navegación, sea en la molienda.

$\mathrm{Su}$ vocación parece ser la de alternativa, aunque a menudo tímida, a las otras dos modalidades energéticas. No aspiran a la inmediatez sino que dibujan un horizonte de futuro esperanzador pero no alcanzable de momento, y a menudo tocado de utopismo: podrían arrancarnos una exclamación como aquella de «¡cuán largo me lo fiáis!....». Y, mientras tanto, reclaman inversiones y subvenciones para su mantenimiento hasta que se alcance el suficiente nivel tecnológico, argumento que vuelven contra ellas sus competidores, quienes además señalan que la pretendida «limpieza» de sus mecanismos de producción energética no es tanta como se presume (por ejemplo, se han dado muchos argumentos que indican la «contaminación paisajística»e incluso geológica de los aerogeneradores, por no hablar de la muerte accidental de aves descuidadas). Por otro lado, se asume que son difíciles de gestionar, de almacenar, de trasportar. En algunos casos se pliegan a la reivindicación pactista de un «crecimiento sostenible» (García, 2005). Por supuesto se oponen a las otras energías y reclaman su espacio, pero lo suelen hacer con una imagen de corrección po- 
lítica, como una oposición que no se encuentra aún preparada para gobernar. Se esfuerzan por dar una autoimagen de ecologismo sonriente, que los ecologistas más radicales califican como un «tranquilizante conformista». Las renovables hallan un magnífico aliado verbal en el prefijo bio-, que parece publicitar su limpieza ecológica y, evidentemente, en el emblemático color verde, asociado en el imaginario colectivo a la naturaleza primaveral, a lo joven, y hasta a la vía libre que los semáforos indican con ese color.

Este tipo de energía se presenta como alternativa a las fósiles y a las nucleares, comenzando por asumir calificativos del tipo «renovables», «limpias» o «verdes», que tienen una clara dimensión eufórica, frente al valor disfórico que presenta, como hemos visto, buena parte del léxico utilizado para referirse a los otros tipos de energías, que son sucias y/o peligrosas, además de tener existencias limitadas en el almacén planetario. Estos calificativos que acompañan a las renovables, por lo tanto, aprovechan la imagen de lo políticamente correcto y generan así una buena retórica de marketing (Salvador, 2011). Además, para la potenciación de su carácter «humano» es clave el hecho de conjugar pasado y futuro, ya que a la vez que responden a un aprovechamiento tradicional de la naturaleza, movilizan también una refinada tecnología que les permite ser promesa de futuro:

L'aprofitament eòlic, hereu d'un gran passat, és ben a prop d'assolir un cost competitiu amb altres fonts d'energia. [...] En el món divers en què vivim, continua creixent $i$, per tant, es presenta amb un gran futur. La generació eòlica no ha fet més que començar. (Prats, 2012: 77)

$\mathrm{Su}$ contraste con las otras fuentes de energía (contraposición que a veces raya en un cierto maniqueísmo) suele ser explicitado en los textos dedicados a presentarlas, que las caracterizan generalmente por oposición a aquellas, como manera de poner de relieve sus ventajas comparativas. Además tienden a acompañarse de ilustraciones vistosas y estéticamente atractivas (la Caixa, 2008). Sin duda estas modalidades de energía son las que con más facilidad pueden ofrecer imágenes idílicas y seductoras para el gran público, lo que constituye uno de los recursos más potentes de su retórica multimodal. Un icono emblemático de las renovables es el girasol, imagen amable y simbólica que se asemeja al astro rey, que simboliza la capacidad de aprovechamiento de los rayos solares y que se asocia con la producción de biodiesel.

Claro que no todo es idílico, y la presentación de las renovables, cuando no se limita a un tono apologético o publicitario, menciona a menudo problemas como el impacto ambiental de los parques eólicos o los desequilibrios económicos que pueden resultar de la producción masiva de biocombustibles, con 
repercusión en las zonas más pobres del mundo. Pero siempre es una opción preferible a la depredación que su principal contrincante, los combustibles, comporta respecto al legado planetario: «És un camp que es troba en constant creixement i desenvolupament i que, sens dubte, suposa l'alternativa real a l'abastiment de l'energia necessària per al nostre dia a dia, sense hipotecar les generacions futures ni esgotar recursos finits que trobem a la Terra» (Jarauta, 2010: 96). Por supuesto, cuando en estos textos, o en las polémicas correspondientes, se hace referencia a la idea de lobbies más o menos ocultos, la imagen se proyecta sobre los otros dos tipos de energías citadas, sin referencias a los intereses económicos que indudablemente existen también detrás de las renovables. Para ello, se vinculan a menudo a su uso familiar o comunal (por ejemplo en la instalación de placas solares o de sistemas geotérmicos de ámbito doméstico) y no tanto a las grandes inversiones necesarias para otro tipo de instalaciones (hidráulicas, undimotrices, mareomotrices, eólicas...), que dependen de presupuestos gubernamentales o de potentes empresas privadas, generalmente subsidiadas con importantes ayudas financieras. Esa coyuntura de encarecimiento a costa del erario público es uno de los argumentos de sus oponentes, que las hacen objeto de intentos de deslegitimación, como los que ha analizado Esperanza Morales (2012), quien concluye que el desarrollo de las renovables se inserta en un espacio antagónico donde se dirime una sucia lucha de poder.

Finalmente, podemos decir que esa «alternativa real» (es decir, realista) ofrecida por las renovables podría asociarse con otros planteamientos actuales. Por ejemplo, con las investigaciones sobre la llamada «química verde», que se propone optimizar la eficacia y fomentar la inocuidad de los productos químicos a fin de equilibrar la relación entre consumo y sostenibilidad: «La química verde, también denominada química beneficiosa para el medio ambiente, se ocupa del diseño de productos y procesos químicos que reducen o eliminan el uso y la producción de sustancias peligrosas» (López Nieto, 2011: 44). En el ámbito francés, asimismo, se produce en la actualidad un intenso debate con la perspectiva de una «transition énergétique» que conduzca a una remodelación a fondo de las disponibilidades energéticas del país, una reordenación prudente de estas en aras de la eficacia y la sostenibilidad del sistema, con una insistencia especial en el desarrollo de las renovables (Conseil National du Debat, 2013). 


\subsection{La teoría de Gaia}

A partir de las obras de James Lovelock y de colaboradores suyos como Lynn Margulis, ha ido desarrollándose en las últimas décadas una teoría de la Tierra como sistema autorregulado que, en el marco del ecologismo actual, constituye una alternativa al uso actual de las energías convencionales, con especial preocupación por el calentamiento global y su principal causante, los combustibles fósiles. Incluso la energía nuclear es vista como un mal menor al lado de las consecuencias del uso desmedido de las fuentes fósiles: «la energía nuclear, por mucho que se la tema, es un remedio necesario» (Lovelock, 2012: 207), al menos hasta que las renovables adquieran la eficiencia suficiente. $Y$ se insiste todavía: «No hay ninguna alternativa a la energía nuclear de fisión hasta que la energía de fusión y formas razonables de energía renovable se confirmen como viables a largo plazo.» (ibid.: 220). Aun con estos matices modalizadores, la teoría supone una alternativa radical al desarrollismo, incluso en sus versiones moderadas: «El concepto humanista de desarrollo sostenible y el concepto cristiano de administradores de la Tierra están viciados por una hybris inconsciente» (ibid.: 200). Como veremos, hay alternativas más radicales, pero esta postura propone una remodelación drástica de las relaciones de la sociedad humana con el planeta que la acoge, y propugna una renuncia a la fe en el crecimiento y en la cornucopia de una abundancia generosa que, para otros, bastaría simplemente con repartir de manera más equitativa o administrar con tiento.

A pesar de que la Tierra, según una expresión coloquial de Margulis, es «una tía muy dura», las perspectivas del crecimiento geométrico de la población mundial y los destrozos del efecto invernadero hacen temer que una auténtica guerra con el planeta desestabilice sin remedio la situación. La alternativa supone «firmar una paz justa» entre iguales que se respetan mutuamente y dejar de ser unos «adolescentes revoltosos» en el seno de la familia. Si bien el formulador de la teoría de Gaia, médico de profesión, se considera un científico y propone algunas líneas de solución muy racionales (control de la demografía, ciudades densas y bien planificadas, ahorro energético, virtualidades futuras de la energía de fusión, etc.), hay en el sustrato de su pensamiento una consideración religiosa o al menos animista, alrededor del mito de la Tierra Madre, un tinte metafísico que irrita a los partidarios de otros movimientos ecologistas: «Algunos adoradores de Gaia y seguidores de la deep ecology han organizado cultos y ceremonias casi religiosas. Y sabemos que la única diferencia entre una secta y la Iglesia es que una Iglesia es una secta que ha tenido éxito...» (Latouche, 2012: 132). 
Parece plausible afirmar, en efecto, que la teoría de Gaia se levanta sobre un sustrato mítico casi panteísta, a juzgar por sus referencias antropomorfizantes al planeta: la Tierra es una «madre» viva, severa y cariñosa al mismo tiempo, cuyo «metabolismo» es delicado y cuya «salud» es preocupante. Incluso el título del citado libro de Lovelock es bien elocuente: La venganza de la Tierra (The revenge of the Earth). En ese marco, los humanos son vistos como hijos que han descuidado la limpieza de ese «hogar planetario» e incluso han dejado de percibir su existencia, tal como el pez ignora el agua que le permite su existencia en la pecera. El léxico de ese tipo es muy recurrente en la exposición de la teoría. Ahora bien, Lovelock insiste en que todo ese lenguaje no es más que un mecanismo metafórico sin validez ontológica, un tinglado expresivo que se pone en marcha como instrumento de persuasión, de movilización social por medio de estímulos que actúan sobre la imaginación, las intuiciones y las emociones:

Sé que personalizar el sistema Tierra como Gaia, como he hecho a menudo y continuaré haciendo en este libro, irrita a los científicamente correctos, pero no me arrepiento, porque necesitamos más que nunca metáforas para conseguir que se difunda la comprensión de la verdadera naturaleza de la Tierra y se entiendan los terribles peligros que nos esperan en el futuro. (Lovelock, 2012: 212)

Se trata, pues, de un recurso retórico, según el autor. Pero es difícil negar que las opciones estilísticas también pueden condicionar en profundidad un estilo de pensamiento.

\subsection{La defensa del decrecimiento}

Si la teoría de Gaia constituye una especie de apelación al imaginario mítico para motivar la conciencia ecologista hacia un respeto al equilibrio del planeta, las propuestas de decrecimiento son llamadas de alerta más estrictamente racionalistas, que asumen la ingrata tarea de «nadar contra corriente» y oponerse radicalmente al sistema sin el apoyo de una mitología, aunque no sin el auxilio de ciertos mecanismos retóricos, como veremos.

En primer lugar, estas propuestas asumen una postura de rechazo a la cultura de la hybris que está profundamente enraizada en la historia de la humanidad y ha sido exacerbada por el consumismo contemporáneo: «La desmesura humana (que los griegos antiguos llamaron hybris, y los cristianos pecado original) no es algo episódico ni secundario en nuestra vida» (Riechman, 2012: 
356). Desde esa perspectiva, que combina la dimensión ética con la lógica de una teoría económica crítica, se denuncia la cultura de la sobreabundancia y el despilfarro de los happy years que, con un «narcisismo antropocéntrico», una «arrogancia epistémica» desmedida y una «ilusión de control» que corresponde más al pensamiento mágico que al racional, han de conducir ineluctablemente, si no se replantea de manera drástica la conexión de la tierra con la vida, a un desastre ecológico global (ibid.: 387-411). La Edad del Antropoceno de la que hablan los geólogos es, efectivamente, una edad de aceleración histórica vertiginosa de la demografía y la tecnología, un período explosivo que desembocará a corto plazo en una crisis ecológica de dimensiones imprevisibles si no se asume con urgencia la apuesta por una estrategia cuyo nombre es tabú: el decrecimiento (Grinevald, 2010).

Lo que está en juego, en el fondo de la cuestión, es ni más ni menos que la «durabilidad de las sociedades humanas». Y para afrontar ese reto no basta con parches, sino que se debe afrontar un desmontaje del sistema de pensamiento que comparten el capitalismo salvaje y la mentalidad judeocristiana, cuyo esquema mental es vectorial y apunta hacia un progreso indefinido, con el Hombre como centro y dueño de la Creación, esquema que quizá subsiste en los subterráneos de la mentalidad marxista. Lo más lúcido de esta crítica es la ampliación de este trust ideológico a unas izquierdas que no han sabido o querido cuestionar el núcleo esencial de esos principios: «La crisi ecològica i climàtica global ha irromput en el plantejament tradicional de l'esquerra marxista i socialdemòcrata, atenta només a les "contradiccions internes" del capitalisme, mentre que les que poguessin venir de fora -del medi natural i del conjunt de la biosfera- no eren preses en consideració» (Azam, 2010: 61). En el fondo de todas esas concepciones subyace una idea de progreso indefinido que ha hecho «olvidar la Naturaleza» y desviar a mirada del coste energético de conseguir energía ( ¡ay, las implacables leyes de la termodinámica!). Para frenar esa deriva es necesario no solo «un Keynes verde» que reconduzca el liberalismo económico y propicie un «decrecimiento sostenible» sino un auténtico «ecosocialismo» que aborde una «construcción social de la naturaleza» (Martínez Alier, 2011).

Seguramente es Serge Latouche el pensador que ha desarrollado más ampliamente, a lo largo de numerosas obras, la apuesta por el decrecimiento. Según este autor, se trata de «un eslogan blasfematorio», un «proyecto iconoclasta» que desafíe al «dogal del marco neoliberal», a «la dictadura del catecismo del pensamiento único y su clerecía», que salga del «círculo vicioso y suicida del crecimiento ilimitado» y «erradique su virus», que espolee a los «pueblos carcomidos por un sentimiento de culpa» y que se enfrente decididamente a 
«la religión del crecimiento» (Latouche, 2012). Como se puede apreciar en esta pequeña muestra de citas, su discurso no regatea la metaforización altisonante, religiosa incluso, al servicio de una estrategia retórica de confrontación y de autopresentación de su actitud como disidencia rebelde que no acepta componendas tales como «la farsa del desarrollo sostenible». Y es que la entonación apologética puede ser necesaria para publicitar una teoría, por muy racional que esta sea. Pero aquí la retórica no alcanza, como ocurría en la teoría de Gaia, a construir parábolas animistas.

Las propuestas positivas que se hacen, en todo caso, están llenas de lógica y buen sentido. Se trata no solo de proponer un ahorro energético sistemático y una nueva lógica fiscal, progresiva, que penalice el sobreconsumo, sino también una reducción del frenesí viajero (el turismo desaforado) o la publicidad generadora de adicción a falsas necesidades, un rechazo de la «obsolescencia programada» que al final desemboca en la caducidad del propio ser humano en el mundo (Latouche, 2014). Todo eso constituye una crítica holística a la lógica del sistema, una crítica a aspectos que guardan relación con el consumo energético, pero que pretende subvertir el sistema en su conjunto e instaurar una nueva lógica económica, social e incluso humanística. Lo hace con la voluntad del líder social que defiende un programa y lo sustenta en una base de conocimiento -informativa, explicativa y reflexiva- sobre la economía neoliberal y su metabolismo industrial.

Para ello el autor se propone una estricta descolonización del imaginario colectivo del «todo-mercado», tal como él mismo verbaliza en numerosas ocasiones. Ese empeño le convierte en un auténtico practicante del análisis crítico del discurso, un analista que pretende desmontar ante sus lectores la ideología dominante que se filtra subrepticiamente en las mentalidades y en las actitudes vitales de la sociedad. Dicho de otro modo: su propósito es una desconstrucción a fondo del marco cognitivo de la ideología desarrollista que limita las mentes, de modo que el ciudadano pueda liberarse de ese corsé falseador y ejercitar un pensamiento creativo. El «desarrollo» es visto así como una palabra «tóxica», precisamente por el aura de simpatía con que se muestra perfumada hasta el extremo de hacerse imperceptible y aparecer como algo natural e inmune a todo cuestionamiento. Latouche es muy lúcido y explícito al respecto. Merece la pena reproducir in extenso sus reflexiones:

Las palabras se enraízan en una historia; están ligadas a representaciones que escapan, muy frecuentemente, a la conciencia de los que las dicen, pero afectan a nuestras emociones [...]. Hay palabras que emocionan al pueblo y cambian el mundo. Libertad y democracia fueron y son aún este tipo de palabras. Pero también hay palabras envenenadas, palabras que se infiltran en 
la sangre como una droga, pervirtiendo el deseo y oscureciendo el juicio. Desarrollo es una de esas palabras tóxicas. Sin embargo esto no se refiere solo a desarrollo y las palabras clave ligadas a él, como Occidente, modernidad, progreso, racionalidad y técnica, sino a todas las palabras clave de la modernidad o de la hipermodernidad: necesidades, mercado, pobreza, producción, recursos, nivel de vida, etcétera. (Latouche, 2009: 139-140)

Esta descolonización del imaginario colectivo, para deseconomizarlo y humanizarlo con propuestas innovadoras, es un leitmotiv del autor, y supone un impulso a contracorriente pero imprescindible y urgente. Urge «reformatear» el imaginario dominante en la sociedad de hoy. Hay que saber, por tanto, explicarlo con eficacia comunicativa y llevarlo persuasivamente al ánimo de los ciudadanos: «El punto clave de la revolución del decrecimiento: expulsar de nuestros espíritus el imperialismo de la economía, pero también reencantar al mundo» (Latouche, 2014: 113).

Esa precisamente es una de las claves de la viabilidad de la operación: compensar la dificultad del pensamiento crítico con la pedagogía oportuna y con un horizonte ilusionante, más allá de las perspectivas pesimistas. Pero no se trata de una mera divulgación de los conocimientos científicos, tecnológicos o economicistas, sino que la persuasión pasa por un ejercicio de humildad epistemológica y de realismo comunicativo: «Es verdad que nuestro programa no puede ser formulado en el lenguaje de los expertos y los tecnócratas» (Latouche, 2009: 141). La dimensión persuasiva de la maniobra exige una retórica que dulcifique el sacrificio exigido y que genere una ilusión rehumanizadora. El autor se refiere en sus obras a la economía del don que se practica en las comunidades primitivas y aún subsiste en ciertos ámbitos de la sociedad actual como una especie de predisposición genética de la especie. Recurre al oxímoron «abundancia frugal», que para él no es menos verosímil que el de «desarrollo sostenible». En la línea del pensamiento de Ivan Illich sobre la felicidad, propone la independización respecto al consumo superfluo, a las necesidades fabricadas, en nombre de ese proyecto socialmente solidario de la abundancia frugal. A fin de cuentas, un programa social necesita una gestión del conocimiento y una persuasión efectiva que lo hagan viable. Sin la adhesión de las voluntades el programa no es realizable, por muy razonable y fundamentado que sea, por muy didácticamente que se presente. Y, por otra parte, no se trata de una mera estratagema de marketing político, sino de una necesidad objetiva impuesta por la complejidad del problema y de sus posibles soluciones, como explica Martínez Alier (2011:382), en un texto donde se propone una dialéctica de interacción entre las identidades del experto y del ciudadano consciente: 
Los problemas ecológicos son complejos, interdisciplinarios. Además muchas veces son nuevos -al haber sido creados por las nuevas industrias. Por eso, ante la gran incertidumbre de muchas cuestiones ecológicas, observamos un fenómeno poco frecuente en otros campos: en las discusiones sobre el riesgo nuclear, sobre el peligro de las dioxinas y furanos, sobre los efectos del calentamiento global, sobre el valor de las semillas campesinas, participan en pie de igualdad los activistas ecologistas con los «expertos» de las universidades o de las empresas.

\section{Para ir concluyendo: textos y contextos del debate energético}

Como hemos visto, el corpus de trabajo utilizado para el análisis corresponde a un género discursivo escrito que combina la intención de divulgación de conocimientos con un propósito persuasivo en el ámbito del debate social sobre las energías. Las identidades de los destinatarios se dibujan así como combinaciones, en proporciones diversas, de ciudadanos conscientes, interesados en el conocimiento, preocupados, amenazados, ilusionables, seducidos por el mito ecológico o la utopía futura... Las tomas de posición de los autores son más o menos explícitas, a veces muy matizadas, incluso veladas por un cierto prurito de independencia, neutralidad y rigor científico, y generalmente adheridas a la figura del experto, pero con frecuencia se puede encontrar, sea explícita o sea entre líneas, una dirección argumentativa, bien como defensa de unas u otras opciones o bien como ataque a alguna(s) de ellas.

Así, los textos que se centran en el tema de las energías alternativas tienden a ser más beligerantes, sobre todo contra las energías fósiles pero muchas veces también -y cuando lo hacen es con más virulencia- contra las nucleares. Al mismo tiempo, estos textos suelen presentar una dimensión programática: más evanescente e inconcreta en el caso de las renovables, que se centran en promesas de un futuro esperanzador de desarrollo tecnológico pero sin perder de vista la humanización; más explícita y contundente en los otros dos tipos que hemos examinado (teoría de Gaia y las del decrecimiento necesario), con propuestas de acción social que se basan en una valoración altamente crítica del panorama actual, y con un discurso del cambio radical, sobre todo por lo que respecta al decrecimiento. Mientras que la teoría de Gaia intenta movilizar más los sentimientos y espolear la imaginación mítica, aunque sin renunciar a un cierto nivel de cientificidad, el tratamiento del decrecimiento, por su parte, combina un análisis más académico con un programa de cambios del sistema en su totalidad, que pasa por la transformación del imaginario colectivo (subversión cognitiva) y por la modificación 
profunda de las actitudes de los ciudadanos (reacción emocional y vital) hacia un nuevo humanismo.

Por lo que respecta a la presentación de las convencionales y la nuclear, cuando no se hace desde una postura de beligerancia clara contra ellas, tiende a ser de tono más comedido, pero también encontramos ahí críticas más o menos abiertas hacia los partidarios de las energías alternativas, como hemos visto: contra el precio a pagar por las renovables (cf. Morales-López, 2012) o, más en general, contra el supuesto radicalismo de grupos ecologistas o de los llamados «lobbies antinucleares». Esta actitud de crítica defensiva (la mejor defensa es el ataque) es más visible en los textos que presentan la energía nuclear que en los que se refieren a las convencionales. La razón parece evidente: los intereses de las nucleares se defienden atacando a sus detractores, que juegan con las cartas retóricas procedentes de activar las representaciones catastrofistas a corto plazo y su imprevisibilidad. Voy a volver, enseguida, sobre este tema.

En lo que se refiere a los intereses petrolíferos, la amenaza de desastre (excepto en los casos de graves accidentes de contaminación de la naturaleza) lo es a largo plazo. En efecto, cuesta visualizar en proximidad el horizonte del cambio climático a pesar de las señales de alerta y de las denuncias, y en cambio el sueño del oro negro, del petróleo fluyendo barato, diseña un paraíso de prosperidad inmediata y de ahí extrae su fuerza de persuasión, poco consciente pero infiltrada en el discurso social dominante y por eso mismo enormemente eficaz. El riesgo se asume así con naturalidad en el imaginario colectivo y basta con mirar hacia otro lado mientras se sigue disfrutando de los happy years. No hace mucho, un gobernante español llegó a declarar públicamente, en el colmo de la falacia irresponsable, que, si los científicos no se atreven a predecir el futuro inmediato, ¿cómo iban a poder hacerlo con el horizonte del cambio climático, tan lejano? Claro que la autoridad científica citada por el estadista no era otro que un familiar suyo. Realmente, los analistas críticos del discurso tomarían esta anécdota como una muestra más de la progresiva conversacionalización del discurso político. Pero esas estrategias populistas no suelen incurrir en un ridículo tan flagrante.

Volviendo ahora a la energía nuclear, cuyos sustos son más fuertes y tienen más resonancia mediática planetaria que los escapes de fuel, las representaciones semánticas del desastre son a menudo apocalípticas, llevan consigo el estigma del pecado bélico original y han de contrarrestarse no solo con la insistencia en su conveniencia económica y su limpieza (por contraste con los combustibles fósiles), sino que también con una exhibición de tecnología avanzada y de control de la seguridad. Esas son las principales líneas de defensa. 
Uno de los textos del corpus utilizado es un libro que lleva el título ambiguo de Nucleares, ¿por qué no? El autor se inviste de un ethos de científico que pretende informar con veracidad y ecuanimidad frente a los "prejuicios» que impiden «un debate sereno». De entrada, el volumen traza la estirpe de los científicos descubridores y presenta - con toda legitimidad, por supuesto- la faceta positiva de la radioactividad y su contribución no solo a la tecnología sino al conocimiento científico. Reproduciré un fragmento que ilustra, con una prosa esmaltada de recursos retóricos, el deslumbramiento producido por la contemplación científica del proceso cosmogenético:

Ese jirón de materia ardiente se fue enfriando y adquiriendo la forma planetaria esférica. De allí surgió la vida, y los seres más evolucionados de ese proceso llamaron al planeta Tierra. [...] ¿Verdad que la energía nuclear no solo es la más natural del mundo sino que tiene su gracia? Estoy rayando en la demagogia; lo sé y no me lo permitiré, pero el asunto es tan bonito... (Lozano Leyva, 2010: 95)

En otro lugar del libro el autor apela a las mejoras en el control de los desechos radiactivos: «Poco a poco se le fue dando la importancia que tiene a ese tipo de residuos, por más que del respeto se pase en ocasiones al pavor irracional» (ibid.: 237). Más adelante emprende un contraataque a un indiscriminado ecologismo que considera «un movimiento político» y entra en explícita controversia con Helen Haldicott y su «alegato furibundo» sobre los efectos biológicos de la radiación. Las energías renovables, por su parte, son objeto de descrédito en función de su elevado coste, o de la contaminación que provocan a pesar de su proclamada limpieza, y se llega a hablar, en referencia a los aerogeneradores, de «dislate eólico». Pero su principal objetivo es neutralizar el miedo cerval que suscita el uso pacífico de la energía nuclear: «El furor antinuclear ha sido tan intenso que ha calado en la población de muchos países desarrollados con una fuerza impresionante» (ibid.: 292).

No he procurado con estas últimas glosas sino poner de manifiesto en qué medida un texto pretendidamente objetivo, y que ciertamente facilita mucha información útil para la divulgación científica de la investigación sobre el tema, no puede sustraerse al espacio del debate y toma postura, como un episodio más de la gestión social de los conocimientos. Pienso que esta última noción va más allá de la nuda divulgación de los saberes, para adentrarse en los entresijos del imaginario colectivo y utiliza representaciones semánticas compartidas, integradas en la doxa común, manejándolas desde los propósitos de cada sector. Todo ello, a fin de moldear en unos sentidos u otros la opinión pública sobre un asunto tan espinoso del diseño de la sociedad actual y futura. 
Por supuesto, las incursiones que realiza el presente trabajo no tienen voluntad de exhaustividad. El corpus de análisis, por ejemplo, es limitado y deja fuera muchos otros géneros de la comunicación social, abiertamente propagandísticos o subrepticiamente publicitarios. Tampoco se ha examinado aquí la actividad real de los lobbies, cuya actuación es, por definición, sigilosa cuando no clandestina. Su presión sobre los gobiernos, sus chantajes y sus cambalaches son otro episodio de la guerra de las energías, factores que una investigación de más envergadura que la presente no podría orillar. Finalmente, habría que confesar de manera explícita - por si acaso el lector no se había apercibido todavía - que este trabajo no aspira a la asepsia, ni siquiera pretende borrar las huellas de la posición adoptada por su autor. Lejos de las hipócritas pretensiones de objetividad, tan solo ha procurado ajustarse a unas reglas metodológicas, marcadas por el oficio de analista del discurso, que garanticen al menos una vía de intersubjetividad razonable. Y todo el resto, claro queda, no es más que una toma de posición en el campo de fuerzas de un debate que sigue abierto.

\section{Referencias bibliográficas $(* *)$}

Amossy, R. (2006 [2000]): L'argumentation dans le discours, París, Armand Colin.

AzaM, G. (2010): «Canvi climàtic i globalització. El compromís de les ONG» en Alıó, M. A. et al. (eds.): Una sola terra. Canvi climàtic i societat civil, Barcelona, Diputació de Barcelona, 57-64 +.

Bruno, J. (2012): «El segle nuclear. De Curie a Merkel i de Becquerel a Fermi», Mètode, 73: 52-59+.

Bustos Guadaño, E. (2014): Metáfora y argumentación: Teoría y práctica, Madrid, Cátedra.

Carvalho, A. (2013 [2011]): «Reporting the climate change crisis» en Allan, S.: The Routledge Companyon to News and Journalism, Londres/Nueva York, Routledge, cap. 44.

CEDISCOR (1992): Un lieu d'inscription de la didacticité: les catadtrophes naturelles dans la presse quotidienne, monográfico de Les carnets du Cediscor 1.

(**) La señalización con el signo + indica que los textos correspondientes se han tomado como bibliografía primaria y secundaria a la vez. 
Conseil National du Débat (2013): «Synthèse des travaux du débat national sur la transition énergétique de la France», París, Sécrétariat Général du Débat National sur la transition énérgetique + .

De Paoli, L. (2013 [2011]): La energía nuclear. Elementos para un debate, Madrid, Alianza, trad. del italiano +.

GARCíA, E. (2005): Medio ambiente y sociedad. La civilización industrial y los límites del planeta. Madrid, Alianza editorial + .

García-Mestres, M.; A. Mateu; M. Domínguez (2012): «L'energia nuclear a la premsa espanyola. Què pensa cada capçalera de l'energia nuclear?», Métode, 73: 60-63 +.

Grinevald, J. (2010): «Clima i petroli, doble amenaça per als consumidors», Alıó, M. A. et al. (eds.): Una sola terra. Canvi climàtic i societat civil. Barcelona, Diputació de Barcelona, 33-43 +.

JARAutA, L. (2010): Les energies renovables, Barcelona, UOC +.

LA CAIXA (2008): Recursos y energías, Barcelona, Eds. 62.

LATouche, S. (2009 [2003]): Decrecimiento y posdesarrollo. El pensamiento creativo contra la economía del absurdo, Barcelona, El viejo topo, trad. del francés + .

- (2012 [2011]): La sociedad de la abundancia frugal. Contrasentidos y controversias del decrecimiento, Barcelona, Icaria, trad. del francés + .

- (20014 [20012]): Hecho para tirar. La irracionalidad de la obsolescencia programada, Barcelona, Octaedro, trad. del francés + .

López Nieto, J. M. (2011): La química verde, Madrid, CSIC +.

LOVELOCK, J. (2009 [2006]): La venganza de la tierra. La teoría de Gaia y el futuro de la humanidad, Barcelona, Planeta, trad. del inglés + .

Lozano Leyva, M. (2009): Nucleares, ¿por qué no?, Barcelona, Debolsillo +.

Martínez Alier, J. (2011 [2004]): El ecologismo de los pobres, Barcelona, Icaria, $2 .^{\mathrm{a}}$ ed. + .

Migliorati, L. (2006): Rischio, una parola pericolosa. Uno studio sulla funzione sociale del rischio, Verona, QuiEdit.

Morales-López, E. (2012): «Análisis de discursos ideológicos en la empresa: La deslegitimación y la defensa de las energías renovables», FORUM. Qualitative Social Research 13/3, Art. 20. <http://www.qualitative-research. net/index.php/fqs/article/view/1864>.

Prats, P. (2012): «L'èxit del vent. La trajectòria de l'energia eólica», Mètode, 73: 71-77+.

Riechmann, J. (2012): Interdependientes y ecodependientes. Ensayos desde la ética ecológica (y hacia ella), Barcelona, Proteus + . 
SALVAdor, V. (2011): «Semàntica lèxica i argumentació: sobre les energies renovables», Articles de didàctica de la llengua i de la literatura, 58 (2012): 28-35.

SEmino, E. (2008): Metaphor in discourse, Cambridge, cup. 